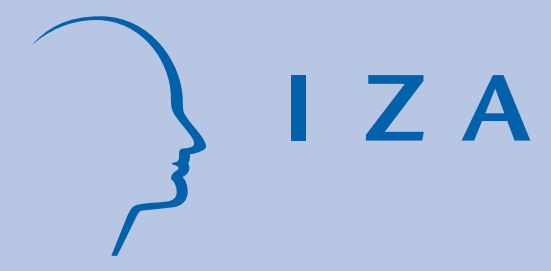

IZA Policy Paper No. 58

Global Health Governance and Tropical Diseases

Till Bärnighausen

David E. Bloom

Salal Humair

May 2013 


\title{
Global Health Governance and Tropical Diseases
}

\author{
Till Bärnighausen \\ Harvard School of Public Health \\ and Africa Centre, University of KwaZulu-Natal \\ David E. Bloom \\ Harvard School of Public Health \\ and IZA \\ Salal Humair \\ Harvard School of Public Health \\ and Lahore University of Management Sciences
}

\author{
Policy Paper No. 58 \\ May 2013
}

IZA

P.O. Box 7240

53072 Bonn

Germany

Phone: +49-228-3894-0
Fax: +49-228-3894-180
E-mail: iza@iza.org

The IZA Policy Paper Series publishes work by IZA staff and network members with immediate relevance for policymakers. Any opinions and views on policy expressed are those of the author(s) and not necessarily those of IZA.

The papers often represent preliminary work and are circulated to encourage discussion. Citation of such a paper should account for its provisional character. A revised version may be available directly from the corresponding author. 
IZA Policy Paper No. 58

May 2013

\section{ABSTRACT}

\section{Global Health Governance and Tropical Diseases}

Global Health Governance (GHG) comprises the means adopted to promote decision making on actions to protect and promote global health, along with the underlying architecture of global health institutions, initiatives, and actors that facilitate these means. GHG is a key factor influencing health outcomes throughout the world. Over the past decade, the GHG system has increased dramatically in size and complexity. In the past half century, GHG has achieved successes against some tropical diseases, but going forward, it faces new challenges. The current GHG system has several weaknesses - lack of participation, transparency, accountability, and efficiency - but the system also has several strengths capacity for innovation, flexibility, and the ability to attract a motivated workforce and to encourage entrepreneurship. To adequately address tropical diseases in the future, GHG reforms will need to address some of the weaknesses while preserving the strengths.

JEL Classification: F35, F68, I18

Keywords: global health governance, tropical disease, development assistance

Corresponding author:

David E. Bloom

Harvard School of Public Health

Department of Global Health and Population

665 Huntington Avenue

Building I 12th Floor, Suite 1202

Boston, MA 02115

USA

E-mail: dbloom@hsph.harvard.edu 


\section{Background}

In 2000 , in the hopes of dramatically reducing poverty and boosting living standards worldwide, the global community adopted eight Millennium Development Goals (MDGs) to be met by 2015. The level to which the world has been successful in achieving these goals is instructive for combating tropical diseases at the global level (United Nations 2011). Three of the MDGs are specific to health, and others indirectly involve health as a stepping stone to a better standard of living. However, recent reports suggest that MDG4 (aiming to reduce child mortality by two-thirds) and MDG 5 (aiming to reduce maternal mortality by three-fourths) are unlikely to be reached by 2015. As for MDG 6, one part of it may be achieved (aiming to halt and reverse the spread of malaria and tuberculosis), but the part that has to do with controlling HIV looks out of reach, as the incidence of new infections continues to outpace the number of people being added to those receiving HIV treatment. It is becoming increasingly clear that reaching these goals hinges on substantially improved and accelerated action by the global community.

What determines these and other critical public health outcomes at the global scale? A key factor is the manner in which the world makes and implements decisions about global health. Broadly, such decisions involve choosing areas of global health the world should focus on (such as health workers, drugs, primary health, specific diseases), raising funds for addressing issues in these areas, creating organizational structures for managing these funds, creating processes for directing these funds to implementing agencies (such as processes for grant or loan solicitation and grant making), monitoring implementing agencies, and evaluating implementation outcomes.

Global health governance comprises the means adopted to promote such decisionmaking and the actions undertaken to pursue common global health goals (Dodgson et al. 2002), along with the underlying architecture of global health institutions, initiatives, and actors (Fidler 2007) that facilitate these means and actions. This architecture plays a vital role in determining health outcomes within countries, and for specific diseases, as evidenced by the advances against HIV in the past decade.

In this chapter, we briefly review the overall system of global health governance and its evolution over the last decade, the emerging challenges it faces, its strengths and weaknesses, and how these strengths and weaknesses affect the system's ability to address tropical diseases in the future.

\section{Global health governance today}

The system of global health governance has changed dramatically since the World Health Organization (WHO) was founded in 1948 (Sridhar 2009). The WHO still remains at the center of this system, but it increasingly shares responsibility and agenda-setting with other organizations. In fact, the current system is highly fragmented, involving a large array of multinational, national, and private organizations with overlapping missions and responsibilities, a diverse set of fundraising and fund disbursement 
mechanisms, and a range of monitoring and evaluation standards (Lee et al. 2002). Table 1 lists a limited selection of the key bilateral, multilateral, and private actors in global health. To this list other actors could be added, such as multi-country networks (e.g., the Group of Eight and the Group of Twenty) and civil society.

One indicator of the influence of these organizations is the level of funding they provide for global health. For instance, consider Table 2 on bilateral official development assistance (ODA), Table 3 on multilateral ODA, and Table 4 on international health grants given by a few US-based foundations in 2010. Even though the numbers in these tables are only a limited snapshot of total giving by some institutions (not including, for instance, the cumulative overseas health expenditures by large non-governmental organizations such as Food for the Poor, Population Services International etc.), they do show that the emergence of new multilateral institutions like the GAVI Alliance and the Global Fund to Fight HIV, Tuberculosis and Malaria (GFATM) has reduced the dominance of WHO, other traditional UN agencies, and some donor countries. Together with the emergence of global private philanthropy - once relatively insignificant but now a significant fraction of all development aid for health (Ravishankar et al. 2009) - and the emergence of dominant players like the Bill \& Melinda Gates Foundation, the landscape of global health has undergone a major transformation in the past decade.

To understand global health governance, we therefore need to understand how these institutions interact with each other, with the private sector, and with civil society to exchange information and technical skills, and establish rules for health programs that promote health worldwide. Moreover, global health governance matters greatly for tropical diseases, which still are rampant in many developing countries (Box 1). The governance system generates funding for these diseases, decides on disease priorities and funding levels, selects the interventions for priority diseases that should receive funding, monitors performance, and gives account of its activities. 
Table 1: A large range of institutions play an important role in global health governance

\begin{tabular}{|c|c|c|c|}
\hline Multilateral institutions & Bilateral institutions & Philanthropic institutions & Humanitarian institutions \\
\hline UN system & AusAID (Australia) & Abbott Fund & (MSF) Médicins Sans Frontières \\
\hline UNAIDS & ADA (Austria) & Bill \& Melinda Gates Foundation & Oxfam \\
\hline UNFPA & CIDA (Canada) & Ford Foundation & (IRC) International Rescue Committee \\
\hline UNICEF & DANIDA (Denmark) & The Bloomberg Family Foundation, Inc. & Save the Children \\
\hline World Health Organization & FINIDA (Finland) & The David and Lucile Packard Foundation & Merlin \\
\hline World Bank & AFD (France) & The John D. and Catherine T. MacArthur Foundation & \\
\hline Regional multi-laterals & GIZ (Germany) & The Merck Company Foundation & \\
\hline African Development Bank & Irish Aid (Ireland) & The Rockefeller Foundation & \\
\hline Asian Development Bank & JICA (Japan) & The Susan Thompson Buffett Foundation & \\
\hline European Bank for Reconstruction and Development & NZAID (New Zealand) & The William and Flora Hewlett Foundation & \\
\hline Inter-American Development Bank & NORAD (Norway) & The William and Sue Gross Family Foundation & \\
\hline Specialized multi-laterals & KOICA (Korea) & Wellcome Trust & \\
\hline Global Fund for AIDS, Tuberculosis, and Malaria & AECID (Spain) & & \\
\hline GAVI Alliance & SIDA (Sweden) & & \\
\hline \multirow[t]{3}{*}{ UNITAID } & SDC (Switzerland) & & \\
\hline & DFID (United Kingdom) & & \\
\hline & USAID (United States) & & \\
\hline
\end{tabular}


Table 2: A few countries account for most public health aid (Overseas development assistance for public health in 2010 by Development Assistance Committee (DAC) countries)

\begin{tabular}{lrr} 
& \multicolumn{2}{c}{ ODA for public health } \\
\cline { 2 - 3 } & \$ million & $\begin{array}{r}\text { of total ODA to } \\
\text { public health }\end{array}$ \\
\hline Total DAC Countries & 15,315 & $13 \%$ \\
\hline United States & 7,809 & $23 \%$ \\
Japan & 2,226 & $13 \%$ \\
Germany & 1,016 & $9 \%$ \\
France & 859 & $8 \%$ \\
Spain & 501 & $11 \%$ \\
Australia & 405 & $11 \%$ \\
Canada & 347 & $9 \%$ \\
Korea & 339 & $19 \%$ \\
United Kingdom & 282 & $6 \%$ \\
Netherlands & 275 & $4 \%$ \\
Denmark & 208 & $12 \%$ \\
Sweden & 195 & $6 \%$ \\
Norway & 194 & $5 \%$ \\
Belgium & 138 & $7 \%$ \\
Finland & 117 & $11 \%$ \\
Switzerland & 114 & $6 \%$ \\
Italy & 109 & $11 \%$ \\
Ireland & 72 & $12 \%$ \\
Luxembourg & 64 & $21 \%$ \\
Austria & 24 & $4 \%$ \\
New Zealand & 14 & $5 \%$ \\
Portugal & 4 & $1 \%$ \\
Greece & 2 & $1 \%$ \\
\hline Source: OECD Statistics 2012. Current prices (data \\
extracted on 18 May 2012). Includes Overseas \\
Development Assistance (ODA) for basic health, \\
population and reproductive health, and water and \\
sanitation. & & \\
& & \\
& & \\
& &
\end{tabular}


Table 3: Numerous multilateral institutions are active in public health (Overseas development assistance for public health in 2010 by multilateral institutions)

ODA

\begin{tabular}{lrr}
\cline { 2 - 3 } & \$ million & \% of ODA to public health \\
\hline Total multilateral funding & 8,963 & $19 \%$ \\
\hline Global Fund & 3,128 & $100 \%$ \\
IDA & 1,827 & $13 \%$ \\
EU Institutions & 1,383 & $10 \%$ \\
GAVI & 697 & $89 \%$ \\
AsDB Special Funds & 356 & $14 \%$ \\
UNFPA & 316 & $100 \%$ \\
UNICEF & 229 & $22 \%$ \\
AfDF & 205 & $9 \%$ \\
UNAIDS & 164 & $67 \%$ \\
WHO & 134 & $37 \%$ \\
OFID & 132 & $21 \%$ \\
AFESD & 109 & $9 \%$ \\
UNRWA & 98 & $18 \%$ \\
Islamic Dev Bank & 76 & $20 \%$ \\
IDB Special Fund & 59 & $8 \%$ \\
UNDP & 25 & $4 \%$
\end{tabular}

Source: OECD Statistics 2012. Current prices (data extracted on 18 May 2012). Includes Overseas Development Assistance (ODA) for basic health, population and reproductive health, and water and sanitation.

Table 4: Gates leads by far private philanthropy for global health (Top 20 U.S. Foundations awarding international grants for health in 2010)

\begin{tabular}{lr}
\hline Foundation & \$ million \\
\hline Bill \& Melinda Gates Foundation & 1,311 \\
The Susan Thompson Buffett Foundation & 82 \\
The Bloomberg Family Foundation, Inc. & 56 \\
The David and Lucile Packard Foundation & 25 \\
Ford Foundation & 22 \\
The Rockefeller Foundation & 22 \\
The William and Flora Hewlett Foundation & 19 \\
The John D. and Catherine T. MacArthur Foundation & 15 \\
The Merck Company Foundation & 12 \\
The William and Sue Gross Family Foundation & 12 \\
Abbott Fund & 10 \\
Howard G. Buffett Foundation & 10 \\
The Bristol-Myers Squibb Foundation, Inc. & 10 \\
The PepsiCo Foundation, Inc. & 8 \\
China Medical Board, Inc. & 7 \\
Ann and Robert H. Lurie Foundation & 6 \\
ExxonMobil Foundation & 6 \\
Conrad N. Hilton Foundation & 6 \\
The Medtronic Foundation & 5 \\
Eli Lilly and Company Foundation & 4 \\
\hline Source: Foundation Center 2012. Current prices (data \\
extracted on 18 May 2012).
\end{tabular}


Box 1: A snapshot of tropical diseases and global health governance

What exactly are "tropical diseases"? We use the term in its traditional definition - that is, diseases that are unique to or are more prevalent in tropical and sub-tropical areas and that typically are infectious. Examples include vaccine-preventable diseases such as smallpox and polio; diseases responsible for major epidemics that have received considerable attention over the past decade, such as HIV, tuberculosis (TB), and malaria; and relatively neglected diseases, such as schistosomiasis and dengue. The "tropics" covers the zone between the Tropic of Cancer and the Tropic of Capricorn; the "sub-tropics" refers to areas just outside that zone (latitudinally). In this chapter, "tropical" refers to both areas, in effect encompassing all developing countries and parts a few developed ones where the disease ecology (e.g., hot climate, abundant rainfall, large number of potential insect vectors, potential vector breeding grounds, large number of potential pathogens) facilitates the transmission of tropical diseases.

Over the past half century, the global health system has had some major successes in the fight against tropical diseases - such as eliminating smallpox, nearly eradicating polio, and developing oral rehydration therapy (ORT) for diarrhea. Smallpox and polio, although not exclusive to the tropics, were major scourges in those regions. In addition to these diseases, the incidence of other infections that are often fatal and extremely common in the tropics has been significantly reduced by the provision of clean water and sanitation, along with ORT.

Because of these successes people in specific populations live longer, commonly into old age, when they become vulnerable to old-age diseases. For instance, in countries with high HIV prevalence, high antiretroviral treatment (ART) coverage brings into existence a "new" population group - aging HIV-infected people receiving ART, who have a bigger risk of cardiovascular disease owing to aging and the interdependent effects of HIV and ART (Mills et al. 2012; Hontelez et al. 2012; Negin et al. 2012).

Thus the past successes in combating tropical diseases are creating new challenges for the future, creating a need to modify the governance system appropriately. Moreover, the continued high incidence and prevalence of other tropical diseases (increasingly concentrated in certain regions) and the greater burden of morbidity (rather than mortality) from these diseases means an outdated global health governance system could lead to poorer health in tropical countries in the future.

\section{Challenges facing the system of global health governance for tropical diseases}

Several issues shape the ability of the global health governance system to successfully prevent, treat, or eliminate tropical diseases. They include the following:

\section{Funding for global health is either stagnant or declining}

Although global health has attracted considerable attention and funding over the past decade, enthusiasm for increased or even stable funding by multilaterals and bilaterals is declining. One reason is the economic contraction brought about by the global financial crisis of 2008 (Bärnighausen et al. 2011). In its wake, the global community has been coping with a slow recovery in the United States, natural disasters in Japan, 
continuing and perhaps worsening perils in the European Union, and a slowdown in China. In the United States, for example, the President's proposed budget for fiscal year 2013 calls for a net reduction in funding for AIDS, counterbalanced only in part by increased funding for TB and malaria. At the global level, bilateral funding for public health continued to rise in 2009 but then fell off in 2010 to below 2008 levels (Table 5). Multilateral funding followed a similar path but stayed about the same from 2009 to 2010. Bilateral funding for malaria, TB, and STDs suffered only a small decline, but the corresponding multilateral funding declined notably. In addition, some funding commitments for 2009 were not even realized, as shown by higher commitment-todisbursement ratios in recent years (Garrett 2012).

Table 5: Development aid for public health is slipping

(Funding commitment for public health and specific tropical diseases)

\begin{tabular}{lcrrrr}
\hline \multicolumn{7}{c}{2006} & 2007 & 2008 & 2009 & 2010 \\
\hline Total public health funding & & & & & \\
Total DAC Countries & 11,731 & 13,980 & 17,040 & 17,792 & 15,315 \\
Total multilaterals & 5,969 & 7,198 & 6,658 & 8,457 & 8,963 \\
Total funding Malaria, TB, STDs including HIVIAIDS & & & \\
Total DAC Countries & 3,335 & 5,321 & 6,370 & 6,436 & 6,203 \\
Total multilaterals & 2,371 & 3,206 & 2,651 & 4,737 & 3,559 \\
\hline Source: OECD Statistics 2012. Current prices (data extracted on 18 May 2012). \\
DAC = Development Assistance Committee, TB = tuberculosis, STD = sexually transmitted diseases
\end{tabular}

Noncommunicable diseases are attracting more attention

Rapid population aging is perhaps the most salient and dynamic aspect of modern demography. To an ever greater extent, people all over the world are living longer and then dying predominantly of noncommunicable diseases (NCDs) - primarily cardiovascular diseases, cancers, chronic obstructive pulmonary diseases, and diabetes - rather than from the infectious diseases that were historically the primary cause of death. This trend is particularly prominent in the developed world, where infectious diseases have become much less of a concern, but population aging is also accelerating in the developing world. As a result, tropical countries are beginning to shoulder a double burden. They still have high rates of infectious diseases (many of which lack a cure) but they are now experiencing increased rates of NCDs as people live longer. Moreover, for several important diseases, successful treatment comes at the price of higher NCD morbidity and mortality.

In recent years, NCDs have registered prominently on the global health agenda. They were the subject of a High-Level meeting of the General Assembly of the United Nations in September 2011, which led to a political commitment from the heads of states to combat them (UN 2011). This was only the second time that a High-Level UN meeting has been dedicated to a health topic (the first time being on HIVIAIDS in 2001). Given that developed countries, which control most of the funding on any issue, are highly concerned about NCDs, it is a distinct possibility that funding for the prevention and 
treatment of tropical diseases may suffer as scarce resources are directed towards NCDs.

Tropical diseases, where they are still prevalent, impose a huge burden

Where tropical diseases are still prevalent, they not only account for a large share of morbidity and mortality (Hotez et al. 2007; Hotez et al. 2006) but they also disproportionately affect certain subsets of the population and impose a significant economic burden.

Setting aside the big three - HIV, TB, and malaria - the group of 17 neglected tropical diseases are endemic in 149 countries and affect over 1 billion people - mostly the poor, and among them, infants and children (Lancet 2010; WHO 2009). Children are particularly badly affected, with such diseases having led to the persistence of high infant mortality rates (IMR) in most developing countries. In the world's least developed countries, the IMR fell from 125 infant deaths per thousand live births in 1980-1985 to 73 today, whereas in the more developed regions it had already declined to 60 by the early 1950 s.

A high IMR has also impeded economic growth by limiting progress on reducing the total fertility rate (TFR). For the poorest countries, the TFR declined from 6.5 children per woman in the early 1980s to 4.1 today, whereas in the more developed regions, the TFR had already declined to 2.8 by the early 1950 s. The combination of a high IMR and low fertility decline has slowed growth of the working-age share of the population, imposing a constant demographic disadvantage on economies. Further, tropical diseases often impede long-run planning, as periodic outbreaks sap local budgets and, at times, cause political chaos (Brulliard 2011).

\section{Defining "good governance"}

Given the challenges that the system of global health governance needs to address to combat tropical diseases over the coming decades, it is important to ask how wellprepared the current system is for this task and how far it needs reform to meet the challenge.

"Good governance" is notoriously difficult to define. Several different definitions have been proposed (Agere 2000; DfID 1997; Leftwich 1993; World Bank 1994; UNDP 1997) and many have been challenged, because they consist of a set of concepts that are too abstract (Poluha and Rosendahl 2002). Rather than debate what constitutes "good governance", we simply use some of the commonly identified attributes of "good governance" to provide an overview of the current thinking on global health governance (United Nations Economic and Social Commission for Asia and the Pacific 2009), and discuss its good and bad aspects. However, our use of these attributes does not imply that we think that they are individually necessary or jointly sufficient for governance to be "good." In fact, in the following discussion of the strengths of the current system of 
global health governance for tropical diseases, we discuss how some of the factors that are identified as reasons for weaknesses can also give rise to beneficial effects.

\section{Weaknesses of the current system of global health governance}

\section{Participation}

The current system of global health governance has been criticized as lacking in participation (Buse et al. 2002) - which the UN defines as involvement of those who are directly or indirectly affected by a health policy through representation in the system of governance that decides the policy (United Nations Economic and Social Commission for Asia and the Pacific 2009). In a narrow sense, the problem arises because some of the key global health institutions are set up by individual donors or private firms who are not required to invite any particular group of people to participate in their decisionmaking - whether or not a group is affected by the decisions.

Prominently, this criticism has been leveled at the Bill \& Melinda Gates Foundation. For instance, Devi Sridhar asserts that one result of the Gates Foundation's generosity towards global health is that almost every university department, think-tank, civil society group, or partnership working on global health issues is directly or indirectly receiving funding from it. She goes on to argue that the new money available for global health, in particular for HIV interventions, "is radically skewing public health and medical programmes towards the issues of greatest concern to the donors, but not necessarily of top priority for people in recipient states [our emphasis]" (Sridhar 2009).

For tropical diseases, one hope for increased participation (Kaul et al. 1999) was the formation of new partnerships, widening the involvement of different public and private groups working across different sectors (Buse et al. 2002). Such partnerships included the Global Fund to Fight AIDS, Tuberculosis, and Malaria; the GAVI Alliance; Roll Back Malaria; the Stop TB Partnership; and the Global Alliance for Improved Nutrition. However, an analysis of the performance of these partnerships (Conway et al. 2006) shows that many of the difficulties that motivated their formation persisted. The partnerships encountered the same difficulties (unrealistic goals, lack of concrete plans to implement goals, and unclear distribution of responsibilities across partners) because of lack of participation in decision making by policymakers from recipient countries.

\section{Transparency}

Another criticism of current global health governance is lack of transparency in making political decisions - which the UN defines as freely available and directly accessible information about decisions, to those who are affected by such decisions (United Nations Economic and Social Commission for Asia and the Pacific 2009). One example of lack of transparency is information on financial flows for treatment of tropical diseases (Sridhar and Batniji 2008). Information on the disbursements of funds for tropical disease programs to recipient nations is often not publicly available and, when it is, is 
incomplete and not standardized across different funders, making it difficult to examine and challenge funding decisions (McCoy et al. 2009). One reason this problem occurs is that the policy actors and their respective roles have changed dramatically over the past years and continue to undergo rapid changes, so it is unclear to most observers who is responsible for which decisions (Buse et al. 2002). Another example of lack of transparency is that most routine monitoring and evaluation data and results, which are collected in tropical disease programs worldwide, are normally not publicly available. Civil society, patients, and researchers outside particular programs are thus unable to independently check claims made by the institutions responsible for the programs.

\section{Accountability}

A third criticism is a lack of accountability - that is, the need for institutions or individuals to account for their decisions and be held responsible for the consequences of the decisions by those who are affected by them. Transparency is a necessary but insufficient condition for accountability. In addition, political actors need to explain the reasons for their decisions to those affected by the decisions, and the affected need to be able to reward or punish the responsible actors (Schedler 1999).

The preamble to the 1946 constitution of WHO assigns responsibility for health to governments (World Health Assembly 2006). Democratically elected policy makers can be held accountable by the public (through elections) and by legislative bodies (through inquiries, impeachment, or votes of no confidence). However, it is far more difficult to hold accountable the non-state actors that have proliferated in recent years in global health - especially the many multilateral, bilateral, philanthropic, and humanitarian donor institutions.

Two recent declarations by donors have called for greater accountability in global health governance.

- The Paris Declaration on Aid Effectiveness calls for "enhancing donors' and partner countries' respective accountability to their citizens and parliaments for their development policies, strategies and performance." (OECD 2005/2008).

- The Accra Agenda for Action supports mutual assessment reviews as an instrument for governments, donors, and the broader public to hold each other accountable for the results of global health investments. "These reviews will be based on country results reporting and information systems complemented with available donor data and credible independent evidence. They will draw on emerging good practice with stronger parliamentary scrutiny and citizen engagement. With them we will hold each other accountable for mutually agreed results in keeping with country development and aid policies." (OECD 2005/2008)

While these declarations are a sign that lack of accountability in global health governance has been identified as a substantial problem, they have yet to be followed 
by concrete actions to build a system of accountability that encompasses all of the key actors in global health.

\section{Effectiveness and efficiency}

A fourth criticism is a lack of effectiveness and efficiency. The reason given for this hypothesized state of the global health governance system is usually a lack of coordination among the different political actors in global health (Garrett 2007; Buse and Walt 1996). Some have characterized the result of unprecedented funding increases and the proliferation of organizations in global health as anarchic (Ruger 2012). While this may be an extreme characterization, the calls for more coordination and control have come from many quarters.

One consequence of poor coordination is duplication of efforts in tropical disease interventions, leading to inefficiencies. For instance, each donor agency usually requires its own funding application and performance reports, even if the different agencies are contributing to funding the same tropical disease program (Bloom 2007). Other consequences include a breakdown of political and technical support of particular tropical disease programs (Conway et al. 2006), along with lost opportunities to learn from each other (Bloom 2007), and to ensure that all necessary components of programs and interventions are funded, appropriately managed, and monitored and evaluated.

Over the past decade, several initiatives have been started to improve coordination among the many initiatives working in global health. At the global level, the Global Task Team on Improving AIDS Coordination among Multilateral Institutions and International Donors (UNAIDS 2005b), the Global Implementation Support Team (GIST) (UNAIDS 2009), the Global Campaign for the Health Millennium Development Goals (Ministry of Foreign Affairs Norway 2010), and the International Health Partnership (ihp+) (ihp+ 2012) have tried to improve coordination among international donors providing aid for tropical disease programs. However, the extent of their success remains unclear. For instance, GIST has been hampered in fulfilling its mission, because of confusion about its role among the participating institutions, such as World Bank, Global Fund, and UNAIDS (Hellevik 2009).

At national levels, institutions such as the National AIDS Commissions (NAC) (Fox et al. 2011), the Global Fund Country Coordination Mechanisms (CCM), and the United Nations Delivering as One initiative (UN 2006) have tried to ensure that various donors' efforts are integrated with countries' health systems and programs. For instance, the Global Fund CCM has brought together representatives of national governments, civil society, the private sector, and multilateral and bilateral donor institutions to help coordinate the development of national proposals, and to help better coordinate Global Fund grants with other national health and broader development programs (Global Fund 2012). Initial evidence shows that the country-level programs have improved coordination and transparency, but that they have not yet succeeded in comprehensively coordinating the efforts of all donors (Spicer et al. 2010). Moreover, in 
some cases the different coordinating initiatives have themselves contributed to coordination problems. For instance, in many countries the Global Fund CCMs became "a new and separate channel which competes with and confuses the role of other bodies" (Shakow 2006).

\section{Strengths of the current system of global health governance}

While several weaknesses plague the current system of system of global health for tropical diseases, it is important to emphasize that some of the underlying structural reasons for these faults have also led to strengths. In particular, it is likely that the simultaneous existence of many institutions working in global health - at different levels, with different but overlapping mandates, and with different organizational histories - has been a source of innovation, flexibility, motivation, and entrepreneurship.

\section{Innovation}

One of the greatest achievements in global health in the past decades has been the provision of ART to millions of HIV-infected patients in developing countries. While a few large initiatives and organizations have played prominent roles in ART scale-up the U.S. President's Emergency Plan for AIDS Relief, the Global Fund, WHO, and UNAIDS - many other institutions have contributed, leading to experimentation with a range of ART delivery models. While the efficiency of exchange of best practices, experiences, and scientific results can be improved, meetings, conferences, and publications have ensured the exchange of knowledge about the performance of the various ART delivery models.

For instance, in South Africa, ART has been funded and provided by Médecins Sans Frontières (MSF), the Elizabeth Glaser Pediatric AIDS Foundation (EGPAF), and the South African Catholic Bishops' Conference, in addition to PEPFAR and the Global Fund. Each of these organizations initially set up their own separate programs - some of them, such as the Catholic Bishops, many years before PEPFAR started providing ART in the country. The lack of coordination across these different organizations allowed for experimentation and testing of alternative models of ART delivery, leading to innovations that are unlikely to have occurred in a single HIV treatment program. For instance, MSF piloted so-called adherence clubs in 2007 to improve ART retention and adherence and give ART patients a forum to share experience and provide each other mutual support. The experience from this innovation - club members are two-thirds less likely to experience ART failure - led the joint government and PEPFAR HIV treatment and care programs in the South African province of the Western Cape to adopt adherence clubs, and it seems likely that similar clubs will be started in other provinces (MSF 2012).

At the global level, the Clinton Health Access Initiative (CHAI) has successfully negotiated substantial price reductions for ART medicines in low-income countries (William J. Clinton Foundation 2012) - an innovative approach to improve access to 
these medicines that is unlikely to have succeeded had CHAI not been added to the institutions that form the global health governance system. It also seems unlikely that the Medicines Patent Pool - which is expected to lower ART prices by facilitating the transfer of licenses for the production of particular drugs from patent holders to companies producing generic drugs (UNITAID 2011) - would have come into existence without the emergence of UNITAID as an organization committed to improving access to treatments and diagnostics for tropical diseases through market interventions.

\section{Flexibility}

The fragmented nature of the global health governance system is likely to have yet another advantage. The simultaneous existence of many institutions of different sizes and with different organizational histories and visions may imply that the system as a whole can react quickly to new needs and demands. For instance, procurement processes (such as for new point-of-care machines) or the hiring of short-term consultants (such as for change management) may be substantially faster in small institutions than in larger ones. Changing the current system to a more centrally organized one will likely lead to increased inertia as large organizations usually need more bureaucratic managerial processes and tend to require more intensive internal coordination.

Smaller organizations - as opposed to larger ones - are also usually better able to meet local demands and needs through their organizational culture, intervention delivery, and interactions with people affected by their actions. For instance, in HIV response community-based organizations (CBOs) have been successful, even if uncoordinated (UNAIDS 2005a), as providers of HIV interventions to particular geographically or culturally defined communities (Chillag et al. 2002). A 2005 UNAIDS report attributes the success of CBOs to their fragmented nature and diversity (UNAIDS 2005a): "These community-based efforts are diverse and involve different skills, vocations and resource bases. But this diversity is one of the great strengths of the community-based response. The varied responses offer many different ways to introduce, sustain and follow up clients as they receive care and treatment. The diversity and complementary services of community organizations help clients gain access to health care that is adapted to their particular needs at the lowest cost, and is often more comprehensive than services offered in the public sector."

\section{Motivation and entrepreneurship}

Another strength of the global health governance system is that it is likely to lead to a large and motivated workforce. The fragmented architecture of the institutions in global health means that more leadership positions need to be filled than in a less fragmented, more centrally controlled system, and that career progression is likely to be accelerated. The good job market and career prospects, in turn, are likely to attract more - and more qualified - nurses, doctors, managers, and researchers. In addition, the existence of institutions with different provenances and commitments is likely to attract a larger variety of people than a system with fewer institutions would. 
Currently, people motivated by humanitarian or religious life goals may find an institution involved in tropical disease intervention funding or implementation just as easily as those motivated by opportunities for entrepreneurship or attainment of positional power. In a less fragmented system - such as one in which WHO would be the main supranational actor - a narrower spectrum of people would find an organization that fit their life goals. Supporting evidence comes from medical schools in developed countries, where in recent years the number of students participating in global health experiences and internships (Shah and Wu 2008) and the number of elective courses, academic tracks, and departments to train and conduct research in global health and tropical diseases has increased dramatically (Furin et al. 2006; Gupta et al. 1999; American Medical Student Association 2012).

\section{The way forward}

A range of proposals are being debated to improve the current system of global health governance:

- Partnerships and coordinating mechanisms could improve participation, transparency, and efficiency (Spicer et al. 2010);

- Frequent, routine publication by all donor institutions of all their committed and disbursed contributions to global health would increase transparency, accountability, and coordination;

- Mutual performance assessment and evaluations among different organizations could increase accountability;

- A strengthening of a central organization, such as WHO or a global health monitoring institute, could improve effectiveness and efficiency (Sridhar 2009); and

- A global health constitution outlining the duties and obligations of actors in global health could improve transparency and effectiveness (Ruger 2012).

However, none of these proposals has been tested, and it seems plausible that some of them could decrease the level of innovation, flexibility, and motivation and entrepreneurship present in the current system. For instance, organizational centralization through a strengthened WHO may not necessarily improve coordination, because "WHO itself is a fragmented organization with a cumbersome governance" (Bloom 2011) and has been criticized for being "ineffective, bureaucratic and political" (Chow 2010). Other proposals, such as further coordinating mechanisms, may themselves duplicate existing efforts and require financial investment and technical capacity, which could be employed for alternative uses in the global health sector. It will thus be important that reforms of the current system of global health governance for tropical diseases are carefully selected and that their progress is monitored. 


\section{Conclusion}

Over the past decade, the system of global health governance has increased dramatically in size and complexity. This has major implications for combating tropical diseases in the future. The system's past successes against tropical diseases may not be replicated in the future because of the challenges in addressing the continued high, and in some areas increasing, morbidity and mortality burdens of tropical diseases; and because of simultaneously increasing disease burdens of NCDs. Funding for tropical disease interventions and global public health in general may be stagnating or declining in the coming decade owing to both economic crises in developed countries and the emergence of new funding priorities, such as NCDs or climate change.

The current global health governance system certainly suffers from a number of weaknesses, such as a lack of participation, low transparency and accountability, and ineffectiveness and inefficiencies stemming from duplication and a lack of coordination among the various institutions that influence global health. However, in thinking of approaches to address these weaknesses, it will be important to preserve the system's strengths - which have provided a fertile ground for innovation, fostered a flexibility that enables actors to react quickly to changes and adapt easily to local conditions, and helped attract and create a highly motivated and entrepreneurial workforce.

\section{Acknowledgement}

The authors gratefully acknowledge Larry Rosenberg at the Harvard School of Public Health for his careful and insightful review of this chapter. 


\section{References}

AGERE, S. 2000. Promoting good governance, London, UK, Commonwealth Secretariat.

AMERICAN MEDICAL STUDENT ASSOCIATION. 2012. International health residency programs [Online]. Available:

http://www.amsa.org/AMSA/Homepage/About/Committees/Global/IHResProgram s.aspx [Accessed 12 June 2012].

BÄRNIGHAUSEN, T., BLOOM, D. E. \& HUMAIR, S. 2011. Going horizontal--shifts in funding of global health interventions. N Engl J Med, 364, 2181-3.

BLOOM, B. R. 2011. WHO needs change. Nature, 473, 143-5.

BLOOM, D. E. 2007. Governing global health. Finance \& Development, December, 3135.

BRULLIARD, N. 2011. Pakistan grapples with dengue outbreak. The Washington Post, 19 September, 2011.

BUSE, K., DRAGER, N., FUSTUKIAN, S. \& LEE, K. 2002. Globalisation and health policy: trends and opportunities. In: LEE, K., BUSE, K. \& FUSTUKIAN, S. (eds.) Health Policy in a Globalising World. Cambridge, UK: Cambridge University Press.

BUSE, K. \& WALT, G. 1996. Aid coordination for health sector reform: a conceptual framework for analysis and assessment. Health Policy, 38, 173-87.

CHILLAG, K., BARTHOLOW, K., CORDEIRO, J., SWANSON, S., PATTERSON, J., STEBBINS, S., WOODSIDE, C. \& SY, F. 2002. Factors affecting the delivery of HIVIAIDS prevention programs by community-based organizations. AIDS Educ Prev, 14, 27-37.

CHOW, J. C. 2010. Is the WHO becoming irrelevant? Foreign Policy, 8 December 2010.

CONWAY, M. D., GUPTA, S. \& PRAKASH, S. 2006. Building better partnerships for global health. McKinsey Quarterly, 1-8.

DFID 1997. Eliminating World Poverty: A Challenge for the $21^{\text {st }}$ Century, London, UK, Department for International Development.

DODGSON, R., LEE, K. \& DRAGER, N. 2002. Global health governance, London, Centre on Global Change and Health, London School of Hygiene \& Tropical Medicine.

FIDLER, D. 2007. Architecture amidst anarchy: global health's quest for governance. Global Health Governance, 1, 1-17.

FOX, A. M., GOLDBERG, A. B., GORE, R. J. \& BARNIGHAUSEN, T. 2011. Conceptual and methodological challenges to measuring political commitment to respond to HIV. J Int AIDS Soc, 14 Suppl 2, S5.

FURIN, J., FARMER, P., WOLF, M., LEVY, B., JUDD, A., PATERNEK, M., HURTADO, R. \& KATZ, J. 2006. A novel training model to address health problems in poor and underserved populations. J Health Care Poor Underserved, 17, 17-24.

GARRETT, L. 2007. The challenge of global health. Foreign Affairs, 86, 14-38.

GARRETT, L. 2012. Money or die. Foreign Affairs, 6 March, 2012.

GLOBAL FUND. 2012. Country Coordinating Mechanisms [Online]. Available: http://www.theglobalfund.org/en/ccm/ [Accessed 12 June 2012]. 
GUPTA, A. R., WELLS, C. K., HORWITZ, R. I., BIA, F. J. \& BARRY, M. 1999. The International Health Program: the fifteen-year experience with Yale University's Internal Medicine Residency Program. Am J Trop Med Hyg, 61, 1019-23.

HELLEVIK, S. B. 2009. 'Making the money work': challenges towards coordination of HIVIAIDS programs in Africa, Houndsmill, Palgrave Macmillan.

HONTELEZ, J., DE VLAS, S., BALTUSSEN, R., NEWELL, M. L., BAKKER, R., TANSER, F., LURIE, M. \& BÄRNIGHAUSEN, T. 2012. The impact of antiretroviral treatment on the age composition of the HIV epidemic in subSaharan Africa. AIDS (in press).

HOTEZ, P. J., MOLYNEUX, D. H., FENWICK, A., KUMARESAN, J., SACHS, S. E., SACHS, J. D. \& SAVIOLI, L. 2007. Control of Neglected Tropical Diseases. New England Journal of Medicine, 357, 1018-1027.

HOTEZ, P. J., MOLYNEUX, D. H., FENWICK, A., OTTESEN, E., EHRLICH SACHS, S. \& SACHS, J. D. 2006. Incorporating a Rapid-Impact Package for Neglected Tropical Diseases with Programs for HIVIAIDS, Tuberculosis, and Malaria. PLoS Med, 3, e102.

IHP+. 2012. Changing the way we work together [Online]. Available: http://www.internationalhealthpartnership.net/en/ [Accessed 12 June 2012].

KAUL, I., GRUNBERG, I. \& STERN, M. 1999. Global public goods: international cooperation in the $21^{\text {st }}$ Century, Oxford, UK, Oxford University Press.

LANCET 2010. Progress and challenges in neglected tropical diseases. The Lancet, 376, 1363.

LEE, K., BUSE, K. \& FUSTUKIAN, S. 2002. Health policy in a globalising world, Cambridge, Cambridge University Press.

LEFTWICH, A. 1993. Governance, Democracy and Development in the Third World. Third World Quarterly, 14, 605-621.

MCCOY, D., CHAND, S. \& SRIDHAR, D. 2009. Global health funding: how much, where it comes from and where it goes. Health Policy Plan, 24, 407-17.

MILLS, E. J., BÄRNIGHAUSEN, T. \& NEGIN, J. 2012. HIV and aging--preparing for the challenges ahead. N Engl J Med, 366, 1270-3.

MINISTRY OF FOREIGN AFFAIRS NORWAY 2010. The Global Campaign for the Health Millennium Development Goals 2010: Putting the Global Strategy for Women's and Children's Health into action, Oslo, Ministry of Foreign Affairs, Norway.

MSF. 2012. Focus on South Africa [Online]. Available: http://www.msf.org.uk/south africa.focus [Accessed 12 June 2012].

NEGIN, J., MILLS, E. J., BÄRNIGHAUSEN, T. \& LUNDGREN, J. D. 2012. Aging with HIV in Africa: the challenges of living longer. Aids.

OECD 2005/2008. The Paris Declaration on Aid Effectiveness and the Accra Agenda for Action, Paris, OECD.

POLUHA, E. \& ROSENDAHL, M. 2002. Contesting 'good' governance:crosscultural perspectives on representation, accountability and public space, London, UK, RouteledgeCurzon.

RAVISHANKAR, N., GUBBINS, P., COOLEY, R. J., LEACH-KEMON, K., MICHAUD, C. M., JAMISON, D. T. \& MURRAY, C. J. L. 2009. Financing of global health: 
tracking development assistance for health from 1990 to 2007. The Lancet, 373, 2113-2124.

RUGER, J. P. 2012. Global health governance as shared health governance. J Epidemiol Community Health, 66, 653-61.

SCHEDLER, A. 1999. Conceptualizing accountability. In: SCHEDLER, A., DIAMOND, L. \& PLATTNER, M. (eds.) The Self-Restraining State: Power and Accountability in New Democracies. London, UK: Lynne Rienner Publishers.

SHAH, S. \& WU, T. 2008. The medical student global health experience: professionalism and ethical implications. J Med Ethics, 34, 375-8.

SHAKOW, A. 2006. Global Fund - World Bank HIVIAIDS programs comparative advantage study, Geneva, Global Fund to Fight AIDS, Tuberculosis and Malaria.

SPICER, N., ALESHKINA, J., BIESMA, R., BRUGHA, R., CACERES, C., CHILUNDO, B., CHKHATARASHVILI, K., HARMER, A., MIEGE, P., MURZALIEVA, G., NDUBANI, P., RUKHADZE, N., SEMIGINA, T., WALSH, A., WALT, G. \& ZHANG, X. 2010. National and subnational HIVIAIDS coordination: are global health initiatives closing the gap between intent and practice? Global Health, 6, 3.

SRIDHAR, D. 2009. Global health -- who can lead? The World Today, 25-26.

SRIDHAR, D. \& BATNIJI, R. 2008. Misfinancing global health: a case for transparency in disbursements and decision making. Lancet, 372, 1185-91.

UN 2006. Delivering as One, New York, United Nations.

UN 2011. Political declaration of the High-level Meeting of the General Assembly on the Prevention and Control of Non-communicable Diseases. New York: United Nations General Assembly High Level Meeting on the Prevention and Control of Non-communicable Diseases, 19-20 September 2011.

UNAIDS 2005a. Expanding access to HIV treatment through community-based organizations, Geneva, UNAIDS.

UNAIDS 2005b. Global Task Team on Improving AIDS Coordination Among Multilateral Institutions and International Donors -- Final report, Geneva, UNAIDS.

UNAIDS 2009. Global Implementation Support Team 2008 end of year review of the annual workplan, Geneva, UNAIDS.

UNDP 1997. Reconceptualising Governance, New York, United Nations Development Programme Management Development and Governance Division.

UNITAID 2011. UNITAID annual report 2011: five years of innovation for better health, Geneva, WHO.

UNITED NATIONS 2011. The Millennium Development Goals Report 2011, New York, United Nations.

UNITED NATIONS ECONOMIC AND SOCIAL COMMISSION FOR ASIA AND THE PACIFIC. 2009. What is good governance? [Online]. Available: http://www.unescap.org/pdd/prs/ProjectActivities/Ongoing/gg/governance.asp [Accessed 12 June 2012].

WHO 2009. Neglected Tropical Diseases. Geneva, Switzerland: World Health Organization.

WILLIAM J. CLINTON FOUNDATION. 2012. Treating HIVIAIDS and malaria: Clinton Health Access Initiative: what we've accomplished [Online]. Available: 
http://www.clintonfoundation.org/what-we-do/clinton-health-access-

initiative/what-we-ve-accomplished [Accessed 12 June 2012].

WORLD BANK 1994. Governance: the World Bank's experience, Washington, D.C.,, World Bank.

WORLD HEALTH ASSEMBLY 2006. Constitution of the World Health Organization. Basic documents, forty-fifth edition, supplement, October 2006. Geneva: WHO. 